\title{
Polycomb repressive complex's evolutionary conserved function: the role of EZH2 status and cellular background
}

\author{
Koraljka Gall Trošelj ${ }^{1 *}$, Renata Novak Kujundzic ${ }^{1}$ and Djurdjica Ugarkovic ${ }^{2}$
}

\begin{abstract}
When assembled in multiprotein polycomb repressive complexes (PRCs), highly evolutionary conserved polycomb group (PCG) proteins epigenetically control gene activity. Although the composition of PRCs may vary considerably, it is well established that the embryonic ectoderm development (EED) 1, suppressor of zeste (SUZ) 12, and methyltransferase enhancer of zeste (EZH2)-containing complex, PRC2, which is abundant in highly proliferative cells (including cancer cells), establishes a repressive methylation mark on histone 3 (H3K27me3). From the perspective of molecular cancer pathogenesis, this effect, when directed towards a promoter of tumor suppressor genes, represents pro-tumorigenic effect. This mode of action was shown in several cancer models. However, EZH2 function extends beyond this scenario. The highly specific cellular background, related to the origin of cell and numerous external stimuli during a given timewindow, may be the trigger for EZH2 interaction with other proteins, not necessarily histones. This is particularly relevant for cancer.

This review provides a critical overview of the evolutional importance of PRC and discusses several important aspects of $\mathrm{EZ} \mathrm{H} 2$ functioning within PRC. The review also deals with mutational studies on EZH2. Due to the existence of several protein (and messenger RNA (mRNA)) isoforms, these mutations were stratified, using the protein sequence which is considered canonical. This approach showed that there is an urgent need for the uniformed positioning of currently known EZH2 mutations (somatic - in tumors, as well as germline mutations in the Weaver's syndrome).

Finally, we discuss EZH2 function with respect to amount of trimethylated H3K27, in a specific cellular milieu, through presenting the most recent data related to $\mathrm{EZ} H 2-\mathrm{H} 3 \mathrm{~K} 27 \mathrm{~m} 3$ relationship in cancer. All these points are significant in considering EZH2 as a therapeutic target.
\end{abstract}

Keywords: EZH2, Polycomb repressive complexes 1-4, Evolution, Mutation, Cancer, H3K27me3

\section{Background}

Post-translational modifications (PTMs) of histone polypeptides contribute to the regulation of gene activity through establishing a specific epigenetic regulatory network [1]. Partly due to PTMs of histones, polycomb group (PcG) proteins can control gene silencing in a considerable part of the genome but only when assembled in multiprotein polycomb repressive complexes (PRCs)-polycomb (Pc)-containing complexes (PRC1) and the enhancer of zeste-containing complexes (PRC2/PRC3/PRC4) [2, 3]. These complexes

\footnotetext{
*Correspondence: troselj@irb.hr

'Division of Molecular Medicine, Laboratory for Epigenomics, Rudjer Boskovic Institute, Bijenicka cesta 54, 10000 Zagreb, Croatia

Full list of author information is available at the end of the article
}

are responsible for the epigenetic memory of gene expression states and play a crucial role in the maintenance and reprogramming of cell types during normal development and during pathophysiological processes (reviewed in [4]).

\section{Enhancer of zeste-containing complexes during evolution Originally identified in the fruit fly Drosophila melanogaster as crucial factors in maintaining the repressed state of developmental regulators such as homebox HOX genes [5], the Pc-group proteins were shown to be highly evolutionary conserved [6]. For example, PRC2 is detected even in uni- cellular eukaryotes, alga Chlamydomonas [7] and yeast Cryptococcus neoformans [8].}


The widespread presence of PRC2, from unicellular organisms to humans, points out its significance for preserving a specific module(s) of gene repression. Evolutionary processes have offered unique ways of PRC2 composing (Table 1): (1) Drosophila contains four core proteins: enhancer of zeste $\mathrm{E}(\mathrm{Z})$; suppressor of zeste $12 \mathrm{SU}(\mathrm{Z}) 12$; extra sex combs (ESC) and the histone binding protein $\mathrm{p} 55$. The $\mathrm{E}(\mathrm{Z})$ protein contains a SET domain which exerts histone lysine methyltransferase activity (KMT), able to catalytically add up to three methyl groups at the target lysine residue K27 of histone 3 (H3). The $\mathrm{E}(\mathrm{Z})$ possesses the SANT domains involved in histone binding and a $C 5$ domain required for interacting with SU(Z)12 [9]; (2) Yeast Cryptococcus neoformans PRC2 has no homolog of SU(Z)12 but contains two additional proteins, Bnd 1 and $\mathrm{Cc} 1$, specific for this species [8]; (3) In nematode Caenorhabditis elegans, only homologs of $E(Z)$ and ESC are found, MES-2 and MES6, respectively. These two proteins make a PRC2 together with a MES-3 protein which has no homolog in any other model organism, and such complex is involved in X-chromosome repression [10]; (4) Plants such as Arabidopsis thaliana, due to gene duplications, have three homologs of $E(Z)$ : CLF, MEA, SWN; three homologs of SU(Z)12: FIS, VRN2, EMF2; and five homologs of p55: MSI1-5, while only one homolog of ESC is present (reviewed in [11]). The combinations of these proteins make at least three distinct PRC2 which are involved in different developmental processes. FIS-PRC2 is similar to its mammalian counterpart and regulates expression of imprinted genes and cell proliferation. EMP-PRC2 acts like Drosophila and mammalian PRC2 in maintaining the repressed state of homeotic genes and, together with the third complex, VNR-PRC2, regulates flower time [11] .

The duplication of $\mathrm{E}(\mathrm{Z})$ gene resulted in two mammalian $\mathrm{E}(\mathrm{Z})$ proteins, $\mathrm{EZH} 1$ and $\mathrm{EZH} 2$ (Table 1), as well as two PRC2 complexes, each containing one of these two EZH- proteins. Accordingly, mammalian PRC2 is composed of four core subunits: EZH1/EZH2, SUZ12, embryonic ectoderm development (EED), and retinoblastoma(Rb)-associated protein 46/48 (RbAp46/48).

Although present in similar PRC2 complexes and controlling an overlapping set of genes, EZH1 and EZH2 are considerably different. PRC2-EZH2, abundant in highly proliferative cells, establishes a repressive $\mathrm{H} 3 \mathrm{~K} 27 \mathrm{me} 3$ mark on PRC2 target genes. PRC2-EZH1, which is abundant in non-dividing cells, likely restores this repressive mark, either as a result of its disappearance due to demethylation or by histone exchange [12].

\section{PRC composition is flexible and cell-type specific}

H3K27 is not the only histone-related substrate for $\mathrm{EZH} 2$, as the PRC-partners may direct the EZH2 to other substrates. For example, an EED isoform 2 (Eed2) and NAD-dependent histone deacetylase Sirt1 specifically associate within the PRC4 which is needed for methylating linker histone H1 (H1K26) [13]. This modification is specific for cancer and undifferentiated embryonic stem (ES) cells.

There is a whole spectrum of variations relating to the dynamic exchange of protein partners (AEBP2, Pcl1/2/3 (PHF1/MTF2/Pcl3t), Jarid2) which may be temporary members of PRC2. This "exchange phenomenon" should not be surprising, as the specific biological effect mediated by PRCs-broad control of gene activity must be achieved very precisely, in a cell-type specific manner and during a controlled time-window (Fig. 1) [14]. For example, Jarid2-a member of Jumonji family of histone demethylases without enzymatic activity-was identified as a part of PRC2, in interaction with Ezh2. Jarid2 binds DNA with a slight preference for GC rich sequences [15] and recruits PcG proteins to target genes [16].

Although there are several possibilities related to flexible ways of composing the content of PRC2 (as discussed), it

Table 1 PRC2 core proteins in model organisms [4, 8]

\begin{tabular}{|c|c|c|c|c|}
\hline $\begin{array}{l}\text { Yeast Crytococcus } \\
\text { neoformans }\end{array}$ & $\begin{array}{l}\text { Nematode } \\
\text { Caenorhabditis } \\
\text { elegans }\end{array}$ & $\begin{array}{l}\text { Plant Arabidopsis } \\
\text { thaliana }\end{array}$ & $\begin{array}{l}\text { Fly Drosophila } \\
\text { melanogaster }\end{array}$ & $\begin{array}{l}\text { Mouse and human } \\
\text { Mus musculus and } \\
\text { Homo sapiens }\end{array}$ \\
\hline \multicolumn{5}{|l|}{ Bnd1, Cc1 } \\
\hline & MES-3 & & & \\
\hline EED1 & MES-6 & $\mathrm{FIE}$ & ESC & EED \\
\hline \multirow[t]{6}{*}{$\mathrm{EZH} 2$} & MES-2 & $C L F$ & $E(Z)$ & $\mathrm{EZH} 1$ \\
\hline & & MEA & & EZH2 \\
\hline & & SWN & & \\
\hline & & FIS2 & SU(Z)12 & SU(Z)12 \\
\hline & & VRN2 & & \\
\hline & & EMF2 & & \\
\hline MSI1 & & MSI1-5 & p55 & $\mathrm{RbAp} 46 / 48$ \\
\hline
\end{tabular}




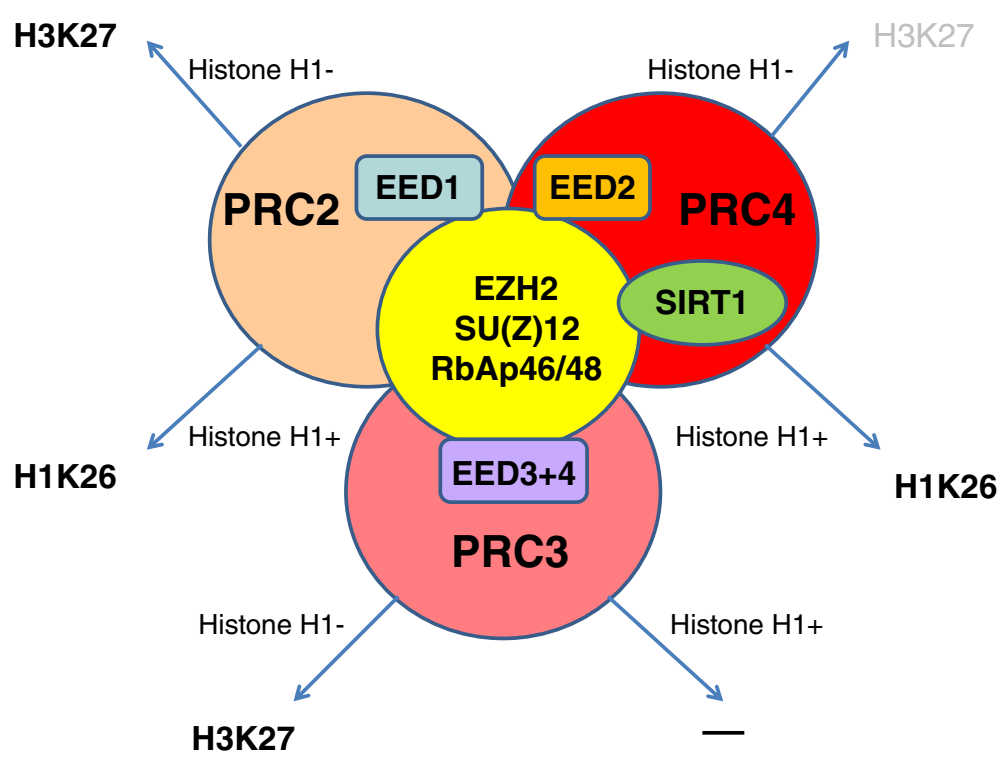

Fig. 1 Association of PRC-EZH2 complexes with different EED isoforms in the presence $(\mathrm{H} 1+)$ or absence $(\mathrm{H} 1-)$ of linker histone $\mathrm{H} 1$ directs $\mathrm{EZH} 2-$ mediated methylation towards H3K27 or H1K26. PRC2, which contains the longest form of EED (EED1), is able to methylate isolated histone H3. When targeted to oligonucleosomes containing linker histone $\mathrm{H} 1$, PRC2 methylates histone $\mathrm{H} 1$ rather than histone H3. PRC3, containing EED3 and EED4, methylates nucleosomal histone $\mathrm{H} 3$, but its methyltransferase activity is inhibited by histone H1. PRC4, containing EED2 and NADdependent deacetylase SIRT1, methylates histone $\mathrm{H} 1$ when present, but has also low methylating capacity towards H3K27 in the absence of histone $\mathrm{H} 1$ (depicted in gray) [13, 14]

is known that the minimum components required for methyltransferase activity of the PRC2/EED-EZH2 complex are EED, EZH2, and SUZ12. The coordinated activity of these proteins is essential for establishing di- and trimethylated H3K27 (H3K27me2/me3) marks which are associated with facultative heterochromatin. These marks present the hallmark histone modification produced by Ezh1 and Ezh2 activity within the PRC2. However, the precise mechanism that governs PRC2 recruitment to chromatin in mammals still needs to be defined.

Recognizing PRC2 functioning as a holoenzyme whose components act together to establish interaction with chromatin in a stepwise manner, Margueron and Reinberg [17] have proposed the following several-steps model: (a) interaction of Jarid2 and AEBP2 with DNA [18, 19]; (b) interaction of RbAp46/48 with histones H3 and H4 [20]; (c) interaction of Eed with H3K27me3 [21]; (d) interaction of Plcs with an unknown histone mark; and (e) interaction of PRC2 subunits with long noncoding RNA (lnc RNA).

These molecular events are highly conserved. In mammals (reviewed in [22]) are well documented through the interaction of lnc RNA X inactive-specific transcript (Xist) with EZH2 and the consequential recruitment of $\mathrm{PRC} 2$ to the X-chromosome leading to its inactivation. In plants, cold induced lnc RNA COLDAIR interacts with plant $\mathrm{E}(\mathrm{Z})$ homolog CLF [23] and recruits PRC2 to the target locus in a way similar to the Xist in mammals. In malignant neoplasms, as shown in gastric cancer, overexpressed lnc RNA 00152 needs to bind to EZH2 in order to exert oncogenic potential through recruiting the PRC2 to promoters of tumor suppressor (TS) genes p15 and p21 [24].

Learning about the evolutional significance of PRC2 in the control of cellular proliferation and differentiation is very important for understanding some basic pathophysiological processes. For example, plants with double mutation of two out of three $\mathrm{E}(\mathrm{Z})$ homologs, clf and swn, undergo normal seed development, but produce a mass of proliferating, undifferentiated tissue resembling cancer, instead of a differentiated shoot after germination [25].

\section{Several aspects of aberrant EZH2 function in cancer}

In humans, the EZH2 mutation may occur in a germline, resulting in clinical features known as the Weaver syndrome, originally described in 1974 [26]. In 2011, mutational analysis of EZH2 in 48 Weaver syndrome patients revealed 44 missense and four truncated mutations. All but two SET domain mutations (R684C and $\mathrm{S} 652 \mathrm{C}$ ), which were present in five and two unrelated individuals, respectively, were distributed throughout the gene, without specific clustering [27]. Only two germline EZH2 mutation-positive individuals developed hematological malignancies: E745K (a lymphoma diagnosed at the age of 13) and an A682T mutation (acute lymphoblastic leukemia (ALL) and neuroblastoma developed at 13 months). 
In 1996, EZH2 was first discovered as a binding partner of Vav oncoprotein in hematological malignancies [28]. These neoplasms were, in addition to breast and prostate cancer, pioneering models for investigating the function and role of EZH2. Its overexpression was first associated with amplification at $7 \mathrm{q} 35$ (more than four $E Z H 2$ copies per cell) in approximately $15 \%$ of the 225 analyzed breast cancers (BCs) [29]. In 2010, EZH2 point mutation (Y641) in SET domain was first found in $7 \%$ of large follicular lymphomas and $22 \%$ of diffuse B cell lymphomas [30]. It was also found in approximately $3 \%$ of melanomas [31]. The discovery of two additional SET domain mutations (A677G and A687V) followed [32, 33].

These "gain of (methyltransferase) function" mutations are responsible for the oncogenic mode of EZH2 action. Contrary to wild-type (WT) EZH2, which loses activity when progressively more methyl groups are incorporated into H3K27, all tested Y641 mutant enzymes (Y641F/N/ $\mathrm{S} / \mathrm{H} / \mathrm{C}$ ) displayed the opposite trend (H3K27me0:me1:me2 kcat/Km ratio: 13:4:1 (WT) vs 1:2:22 (Y641) [34]. Since one cell possesses both wild- and mutant types of the EZH2 allele, there appears to be dependency on the coordinated activity of both alleles.

Aberrant activity of PRC2 can result from aberrant EZH2 expression, without chromosomal amplification, as a consequence of diverse aberrations which are present in cancer cells. For example, comprehensive analyses of transcriptome and epigenome data obtained from adult T cell leukemia (ATL) cell lines, normal CD4 ${ }^{+} \mathrm{T}$ cells, human T-lymphotropic virus type 1 (HTLV-1)immortalized and transformed $\mathrm{T}$ cells show the importance of increased, NF- $\mathrm{kB}$ dependent expression of EZH2 (both RelA and RelB were shown to be bound to EZH2 promoter) which further activates NF- $\mathrm{BB}$ through silencing of microRNA (miR)-31. Of interest for this model, H3K27me3 was enriched in the promoter of transcriptionally downregulated H3K27me3 demethylase KDM6B (JMJD3), which also may compromise the balance between epigenetic "writers" and "erasers." It was shown that HTLV-1 protein Tax binds to EZH2, without affecting the PRC2 composition. As a result, the pattern of H3K27me3 accumulation significantly overlaps in ATL- and HTLV-1-immortalized cells. Since HTLV-1 infected cells are sensitive to EZH2 inhibition, this research data may be a ground for introducing EZH2 inhibitors for treating asymptomatic, HTLV-1 infected individuals [35].

Hepatitis B virus (HBV)-associated hepatocellular cancer (HCC) represents another interesting model for studying the abberant expression of tumor suppresive miRs in respect to PRC2 activity in a setting of prolonged viral infection. In the HBV-HCC model, coexpression of transcription factor (TF) YY1 and EZH2 are associated with silencing several, multiple YY1 binding sites-containing suppressive miRs and relate to short disease-free survival [36]. YY1 can interact with both EZH2 and SUZ12 [37] and recruits the PRC2 complex to chromatin. The discovery of this oncogenic mechanism, which was responsible for silencing of five highly NF- $\mathrm{kB}$ suppresive miRs, pointed out the importance of coordinated action of YY1 and EZH2 for focal reshaping of chromatin.

The already mentioned tumor suppressor miR-31 was shown to be silenced in prostate cancer cells through presence of H3K27me3 on its promoter [38]. The absence of miR-31 in $\mathrm{t}(4 ; 14)$ positive multiple myeloma (MM) patients (15-20\%) allows for pro-oncogenic activity of its target-multiple myeloma set domain methyltransferase (MMSET), which establishes histone mark H3K36me2 and induces a global reduction H3K27me3 [39]. However, in this scenario, specific loci exhibit enhanced recruitment of EZH2, leading to misregulation of specific polycomb target genes.

It was recently shown that $\mathrm{H} 3 \mathrm{~K} 27 \mathrm{me} 3$ enriched genes in experimental models of MM significantly overlap with underexpressed genes in MM patients with poor survival [40]. Of interest, although applying EZH2 inhibitor, E7438 induces reproducible re-expression of crucial epithelial tumor suppressor genes (including $C D H 1$ ) in 13 tested MM cell lines, there are many questions arising from a high variability in E7438 sensitivity in the proliferation assays [41].

All these examples show that there are many factors that may influence EZH2 and are influenced by EZH2. Accordingly, EZH2 pharmacological inhibition may have various effects.

In addition to "gain of function" mutations, there are also EZH2 "loss of function" mutations discovered in hematological malignancies originating from myeloid cells, commonly joined with unipaternal disomy (UPD) [42]. The proposed model of EZH2 "loss of function" mutations (of which the majority were found in the SET domain) attributes their contribution to be forming cancer stem cells, via HOXA9 mediated self-renewal of myeloid progenitors. A complex in vivo model (transplantation of bone marrow (BM) cells from 8-12-week-old CreERT;Ezh2fl/fl CD45.2 mice into lethally irradiated CD45.1 recipient mice and deletion of Ezh2 at 6 to 8 weeks posttransplantation) reveals that complete lack of EZH2 activity in hematopoietic stem cells (HSCs) predisposed mice to heterogenous malignancies (MDS, MDS/MPN, MDS/ MPN associated with trombocytosis, and $\mathrm{T}$ cell acute lymphoblastic leukemia). The same experimental model showed locus-specific repositioning of EZH1 to EZH2 targets (3605 genes in contrast to 969 "EZH2 targets only") and its ability to re-repress them during prolonged period of time (9 months) [43]. All these data clearly indicate that 
EZH2 function, in both physiological process and in various pathogenic events, must be studied in a broad context, keeping in mind that its binding partners contribute to specificity of its functioning, in a particular cellular setting.

\section{Which mutation is "the right one"?}

The problem that occurs when comparing the results of EZH2 mutational analyses coming from different sources relates to amino acids positioning in the EZH2 sequence. For example, "gain of function" mutations are listed according to the protein sequence that is considered "canonical" (UniProtBD/Swiss-Prot Q 15910-1; 746 amino acids (AA)) [30, 32, 33]. On the other hand, "loss of function" [34], and germline mutations [27], were positioned according to the longest protein isoform of EZH2 (UniProtBD/Swiss- Prot Q 15910-2; 751 AA). The absence of uniformity may be confusing. For example, the already mentioned inherited mutation discovered in the Weaver syndrome patient suffering from ALL (A682T) [27] corresponds to alanine 677 mutation (A677G) in B cell lymphoma [30]. Similarly, a rare $\mathrm{EZH} 2$ breast cancer mutation described as A692V [44] corresponds to B cell lymphoma mutation at position 687 [33]. The difference of five amino acids corresponds to the difference between Q15910-1 and Q15910-2 isoforms (HP $\rightarrow$ HRKCNYS), which are identical in the first 297 amino acids (Fig. 2). The basic data on currently known EZH2 protein isoforms and their coding messenger RNAs (mRNAs) are presented in Table 2. The hope is that future presentations of EZH2 isoforms and the positions of mutated codons will be done in a more uniform manner.

Stratified presentation of mutations published in previous studies [27, 30-34, 44] reveals identical type/position of three germline (G) and three somatic (S) mutations. One mutation was reported as oncogenic (lymphoma; S\&G:A677T), and two other ones were reported as suppressive (S:E741fs $\rightarrow$ G:E741K; S:R679C/ $\mathrm{P} \rightarrow \mathrm{G}: \mathrm{R} 679 \mathrm{C} / \mathrm{H}$ ) (Fig. 2; UniProtBD/Swiss- Prot Q 15910-1). It remains to be seen whether any of these EZH2 mutations act as a "Janus" mutation in the RET protooncogene (germline mutation that acts simultaneously as both a gain-of-function and a loss-of-function mutation) [45].

Data related to the functional differences of EZH2 splice variants is scarce. The expression level of EZH2 transcript variants 1 and 3 was shown to be similar in 22 tested human tissue samples. Forced expression of corresponding protein isoforms (Q 15910-2 and Q 15910-3; Table 2) in pancreatic cancer cells revealed that each protein isoform has an affinity for a preferential gene cluster (36.3 and $47.6 \%$ genes were repressed by EZH2 $\beta$ (Q 15910-3) and EZH2 $\alpha$ (Q 15910-2), respectively, while repression of remaining $16.1 \%$ genes needed the presence of both isoforms) [46]. The data indicates that the different EZH2 cell-specific mRNAs, and protein isoforms may have functional importance, including for the clinic, as already shown for some other genes [47, 48].

\section{Specific cellular background and multiple roles of EZH2} EZH2 binding affinity for both histones and non-histone substrates may partially explain why targeted silencing of EZH2 leads to bidirectional change of gene expression, in a specific cellular context-dependent manner [49]. Some examples are: (1) EZH2 binds to RelA/RelB in $\mathrm{BC}$ cells and regulates the NF- $\mathrm{kB}$ target genes in a positive $(I L-6, T N F)$ or negative way, depending on estrogen receptor (ER) status rather than the EZH2 histone methyltransferase activity. In ER+ BC cells, ER recruits PRC2 for enforcing a repressive chromatin modification at NF- $\mathrm{kB}$ target genes. (2) In squamous cell carcinomas (SCC), EZH2, through repressing IкB kinase $\alpha$ (IKK1) promoter, leads to IKK1 silencing [50]. In any other types of tumor, this would be a suppressive effect. However, it is oncogenic in SCCs because IкB kinase $\alpha$ has a tumor suppressive role in these tumors [51]. 3. Finally, it seems that EZH2 catalytical activity does not have the most significant role for an increased rate of growth in some SWI/ SNF-mutant cancers [52]. Instead, the stabilization of PRC2, dependent on EZH2 threonine 487 (T487) phosphorylation (Prot Q 15910-1), seems to be essential, at least in this particular scenario [53]. However, this phenomenon may be abrogated by presence of mutant K-ras.

In non-small cell lung cancer (NSCLC), the type of substitution at 12th codon of K-ras determines activation of a specific pro-proliferative signaling pathway. Cells with K-RAS ${ }^{\text {G12D/+ }}$ or K-RAS ${ }^{\mathrm{G} 12 \mathrm{C} /+}$ have primarily activated PI3/AKT and MEK/ERK signaling pathways, respectively [54]. Accordingly, activation of EZH2, which was shown to be dependent on K-ras mutants, may be inhibited by specific inhibitors of mutation-type dependent downstream signals. This is important because one of significant pro-oncogenic activities of EZH2 depends on activated AKT which, through EZH2, phosphorylates and activates oncogenic STAT3 [55] .

A generation of mice with Cre-recombinase-activated conditional oncogenic K-ras allele (K-ras ${ }^{\mathrm{G} 12 \mathrm{D} /+}$ ), along with either mild Ezh2 overexpression (Ezh2 ${ }^{\mathrm{LSL}}$ ) or lost PRC2 function achieved by conditional deletion of Eed1 $\left(\mathrm{Eed}^{\mathrm{fl} / \mathrm{fl}}\right)$, joined with conditional deletion of p53 $\left(\operatorname{Trp} 53^{\mathrm{fl} / \mathrm{fl}}\right)$, revealed that the genotype $\mathrm{K}-\operatorname{ras}^{\mathrm{G} 12 \mathrm{D} /+}$; $\operatorname{Trp} 53^{\mathrm{fl} / \mathrm{fl}}$; and $\mathrm{Eed}^{\mathrm{fl} / \mathrm{fl}}$ develops the most aggressive, mucinous NSCLC. In this genetic setting, which is relevant for human pathology (mutations of K-RAS and P53 are present in 35 and $40 \%$ NSCLCs, respectively), Eed1 acts as a tumor suppressor gene. In the presence of WTp53, 


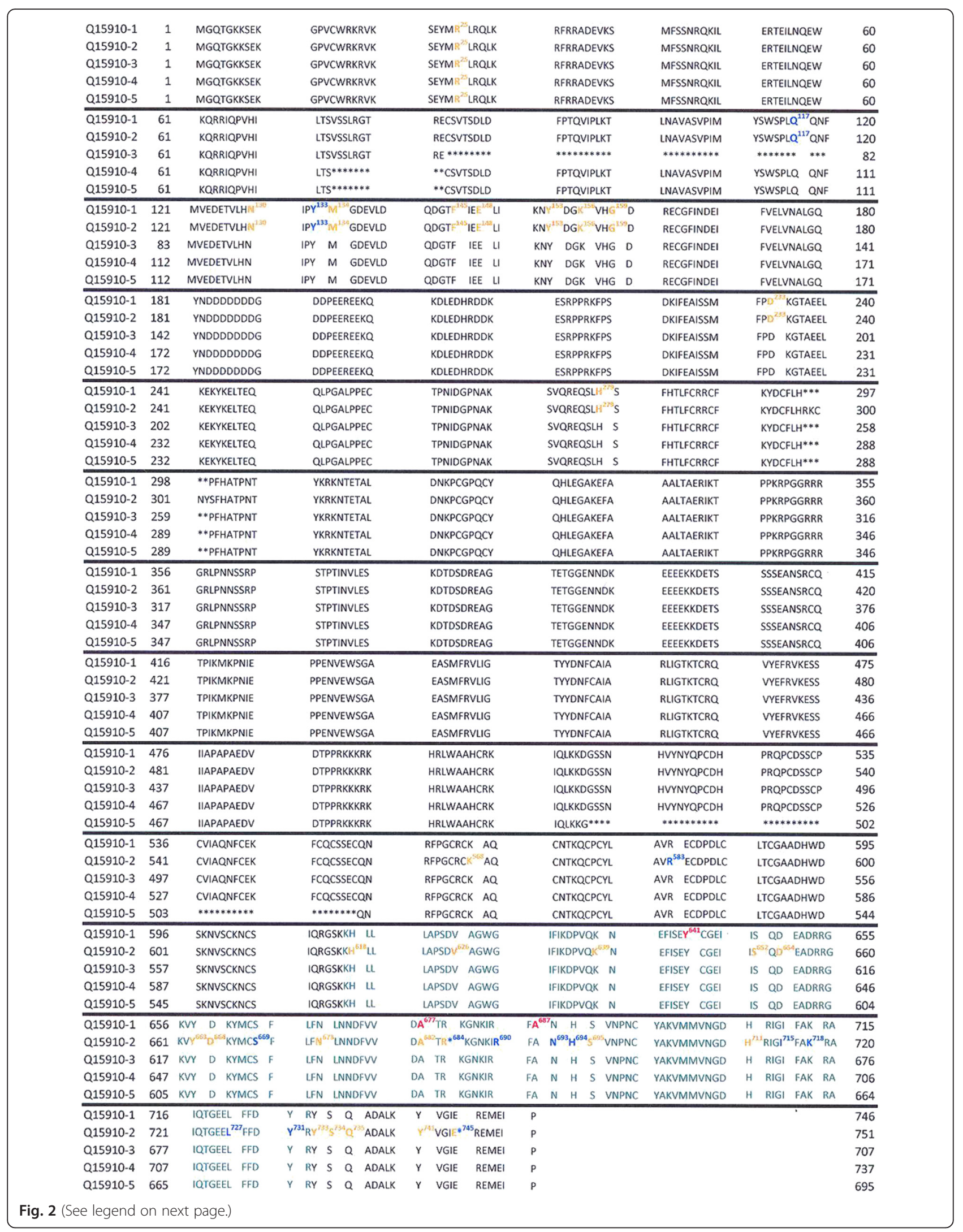


(See figure on previous page.)

Fig. 2 Alignment of five EZH2 isoforms protein sequences (UniProt). SET domain is shown in green (Q15910-1 AA 612-727; Q15910-2 AA 617732; Q15910-3 AA 573-688; Q15910-4 AA 603-718; Q15910-5 AA 561-676). Germline mutations [27] are shown in orange, "loss of function" mutations [42] in blue, and "gain of function" mutations [26, 30, 32, 33, 44] in red. All mutations listed in the cited references are marked on respective isoform sequences, highlighting the lack of uniformity in annotating mutations according to consensus sequence (Q15910-1). Therefore, mutation A677 (in isoform 1) is listed as somatic, activating mutation and at the same time, annotated as mutation A682 (in isoform 2), has been listed as germline mutation which was discovered in the Weaver syndrome patient who developed ALL and neuroblastoma in early childhood. This is in accord with the oncogenic potential of this mutation. Inactivating mutations R684 in isoform 2 (corresponding to R679 in isoform 1) and E745 in isoform 2 (corresponding to E740 in isoform 1) have been shown to be mutated in Weaver syndrome patients. None of the five patients with inherited mutation R684C (present as somatic mutation in one 82-year-old patient suffering from chronic myelomonocytic leukemia) developed malignant disease at the time of testing for germline mutation of EZH2. Germline mutation E745K (isoform 2) was present in a patient who developed nonHodgkins lymphoma at the age of 13 . Somatic mutation of this codon was detected in one patient with chronic myeloic leukemia during blast crisis.

$\operatorname{Kras}^{\mathrm{G} 12 \mathrm{D} /+} ; \mathrm{Eed}^{\mathrm{fl} / \mathrm{fl}}$ mice developed NSCLs which were, although smaller than $\mathrm{Kras}^{\mathrm{G} 12 \mathrm{D} /+} / \mathrm{Ezh} 2^{\mathrm{LSL}}$ tumors, characterized by life incompatible inflammation in alvelolar spaces. In vitro, the inhibition of EZH2, achieved through the prolonged exposure of human K-RASmutant NSCLC cells to an inhibitor of EZH2 catalytic activity (GSK126), resulted in a strong increase of inflammatory genes (i.e., IL-6) associated with microenvironment-regulated tumor progression. Based on these and many more results coming from the cited study [56], it was suggested that PRC2 can hold opposing functions, depending on the stage of tumor development and the genetic make-up of the tumors (as presented here), with respect to p53 status. Accordingly, this and other studies clearly show a rationale for the combined application of PRC2 inhibitors and antiinflammatory drugs. In the model of hematopoietic stem cells, EZH2 loss was recently shown to result in the expression of fetal gene signature, including upregulation of fetal-specific Lin28b which encodes RNAbinding protein that prevents maturation of miR-let-7 which is specific for adult HSCs. Activation of fetal gene signature in $\mathrm{EZH} 2$-deficient adult bone marrow HSCs was shown to result in fetal-like high self-renewal capacity and increased propensity to undergo malignant transformation [57]. Enforced expression of Lin28b has been reported to impair $\mathrm{T}$ cell development in vivo, leading to developing an aggressive peripheral $\mathrm{T}$ cell lymphoma, accompanied by a decrease in let-7 expression, surge of IL-6, activation of NF- $\mathrm{kB}$, and infiltration of B cells leading to an inflammatory microenvironment [58].

The proper anti-tumor function of $\mathrm{T}$ cells depends on the differentiation of naive and memory $\mathrm{T}$ cells into effector cells. Metabolic switch from oxidative phosphorylation to aerobic glycolysis is mandatory for $\mathrm{T}$ cell activation. Highly glycolytic ovarian cancer cells were recently shown to impose glucose restriction on tumorinfiltrating $\mathrm{T}$ cells, thereby inhibiting this metabolic switch. Low glucose availability results in upregulation of EZH2-targeting miR-26a and miR-101 with subsequent EZH2 downregulation. This is consequential for $\mathrm{T}$ cell effector function, since EZH2 activates the Notch pathway that stimulates $\mathrm{T}$ cell polyfunctional cytokine expression and their survival, which was shown to be impaired in many tumors. These results point to the different effects that systemic inhibition of EZH2 may have on tumor cells and $\mathrm{T}$ cells, warranting special caution when considering such epigenetic intervention [59].

\section{H3K27me3 as a measure of EZH2 activity}

There are many EZH2-related scenarios and none of them is simple. When analyzed in five well-defined subtypes of $\mathrm{BC}$, the highest $\mathrm{EZH} 2$ expression, joined with a very low level of $\mathrm{H} 3 \mathrm{~K} 27 \mathrm{me} 3$, was found in basal-like, triple negative $\mathrm{BC}[60]$, known for its distinctly aggressive nature [61]. This inverted pattern (EZH2 $\uparrow$, H3K27me3 $\downarrow$ ), further confirmed in a basal-like BC cell lines, represents the negative prognostic marker in $\mathrm{BC}$ patients $[60,62]$. There are a few studies in which a

Table 2 Human EZH2: five proteins and corresponding mRNA splice variants are currently deposited. Although mutational analyses of EZH2 refer to the ordinal number of mutated amino acids, they rarely identify the isoform which is the basis for numbering them

\begin{tabular}{lllllll}
\hline $\begin{array}{l}\text { UniProtBD/ } \\
\text { Swiss-Prot }\end{array}$ & $\begin{array}{l}\text { Transcript } \\
\text { variants (TV) }\end{array}$ & mRNA NCBI & $\begin{array}{l}\text { mRNA } \\
\text { length (nt) }\end{array}$ & Coding region & $\begin{array}{l}\text { cDNA I } \\
\text { ength (nt) }\end{array}$ & $\begin{array}{l}\text { Protein } \\
\text { size (AA) }\end{array}$ \\
\hline $15910-1$ & TV3 & NM_001203247.1 & 2708 & $194-2434$ & 2241 & 746 \\
$15910-2$ & TV1 & NM_004456.4 & 2723 & $194-2449$ & 2256 & 751 \\
$15910-3$ & TV2 & NM_152998.2 & 2591 & $194-2317$ & 2124 & 707 \\
$15910-4$ & TV4 & NM_001203248.1 & 2681 & $194-2407$ & 2214 & 737 \\
$15910-5$ & TV5 & NM_001203249.1 & 2682 & $321-2408$ & 2088 & 695 \\
\hline
\end{tabular}


decreased level of H3K27me3 was associated with a poor outcome in different malignant tumors (breast, ovary, pancreas, lung) $[63,64]$. These results, together with those showing that solid tumors (prostate, breast) can develop even in the absence of Ezh2 [44], challenge the strength of $\mathrm{EZH} 2$ as the epigenetic driver of oncogenesis [65], at least in the stated tumor types. This data, supported by a broad analysis of human transcriptome data sets (131 prostate cancers (plus 19 metastases), $146 \mathrm{BCs}$ ) indicates that EZH2 expression "follows" the rate of cellular division, is under control of proliferation cues, and "passively" correlates with proliferation and proliferation markers (primarily Ki-67), in order to maintain the cellular level of H3K27me3.

It was suggested that EZH2 overexpression should be considered from two perspectives: (a) through coupling its expression to proliferation and (b) coupling it to proliferation-independent, amplification-related, copy number-driven, expression [44].

However, this approach should be considered in a specific cellular milieu and should not be applied nonselectively, to all types of malignant tumors:

In many systems, EZH2 supports stem cell maintenance by repressing differentiation. But, in neural crest stem cells (NCSCs), which are the source of melanocytes, it specifically promotes the acquisition of a mesenchymal fate [66]. EZH2 is essential for melanoma initiation and growth, during which EZH2 and Ki-67 positive cells significantly correlate, just like in the $\mathrm{BC}$ model. Increased expression of EZH2 in melanoma strongly correlates with shorter overall survival (OS) and earlier development of distant metastases [67, 68]. EZH2-mediated repression of the tumor suppressor adenosylmethionine decarboxylase 1 (AMD1) appears to be of the greatest importance for these processes. The role of this gene, as well as its repressor, EZH2, needs to be further investigated and validated.

\section{Conclusions}

The function of any biomolecule must be considered in a specific cellular setting. Accordingly, cell-type specific signals which constantly change during adaptive responses to various stimuli are the basis of an epigenomic dynamic network, reflecting both-the type of the cell and the type of the stimulus in a given time-window. Understanding the exact role of EZH2 in such a complex system is not an easy task. There is convincing mechanicistic data confirming the oncogenic function of EZH2 related to PRC2 functioning (repression of tumor suppressor genes through H3K27me3) in several biological models. Numerous studies, however, interpret an increased EZH2 immunoreactivity score as an unquestionable oncogenic event. The fact that the score does not necessarily reflect the presence of a functional PRC2 and/or its increased recruitment to chromatin seems to be all too often neglected.
When considering EZH2 as a therapeutic agent, one must take into account these parameters, together with an understanding of the functional consequences of EZH2 mutations and the cancer patient's specific cellular oncometabolome with respect to systemic inflammatory reactions.

While the targeted inhibition of EZH2 catalytic activity emerges as a promising therapeutic intervention, it still has many other cellular-specific functions which must be carefully evaluated to avoid broad side effects. These issues are further discussed in a broader context elsewhere in this issue of Clinical Epigenetics [69].

\begin{abstract}
Abbreviations
AA: amino acid; ALL: acute lymphoblastic leukemia;

AMD1: adenosylmethionine decarboxylase 1; ATL: adult T cell leukemia;

BM: bone marrow; BC: breast cancer; $E(Z)$ : enhancer of zeste; EED: embryonic ectoderm development; ER: estrogen receptor; ES cells: embryonic stem cells; ESC: extra sex combs; EZH2: enhancer of zeste homolog 2; G: germline; H3K27: lysine 27 of histone 3; HBV: hepatitis B virus; HOX: homebox; HSC: hematopoietic stem cell; HTLV-1: human T-lymphotropic virus type 1; IKK1: IKB kinase a; LL-6: interleukin-6; KMT: Iysine methyltransferase; Inc RNA: long non-coding RNA; MDS: myelodisplastic syndrome; miR: microRNA; MM: multiple myeloma; MMSET: multiple myeloma set domain methyltransferase; MPN: myeloproliferative neoplasms; NCSCs: neural crest stem cells; NSCLC: non-small cell lung cancer; OS: overall survival; PcG: polycomb group; PRCs: polycomb repressive complexes; PTMs: posttranslational modifications; RbAp46/48: retinoblastoma(Rb)-associated protein 46/48; S: somatic; SCC: squamous cell carcinoma; SU(Z)12: suppressor of zeste 12; TF: transcription factor; TS: tumor suppressor; UPD: unipaternal disomy; WT: wild-type; Xist: X inactive-specific transcript.
\end{abstract}

\section{Competing interests}

The authors declare that they have no competing interests.

\section{Authors' contributions}

All authors contributed to writing the paper: DU-EZH2 and evolution; RNK - EZH2 and its complexing within various PRCs; KGT_disease-related aspects of EZH2 and mutational analysis of presented data, in addition to composing the text. All authors share full responsibility for the text and illustrations in this review. All authors read and approved the final version of this manuscript.

\section{Acknowledgements}

This work was supported by COST Action CM1406-Epigenetic Chemical Biology (EPICHEM) and Croatian Science Foundation Project IP-2014-09-3733 (PI: DU). Our special note of gratitude goes to Mr. Aaron Etra who helped us with language issues.

\section{Author details}

'Division of Molecular Medicine, Laboratory for Epigenomics, Rudjer Boskovic Institute, Bijenicka cesta 54, 10000 Zagreb, Croatia. ${ }^{2}$ Division of Molecular Biology, Laboratory for Evolutionary Genetics, Rudjer Boskovic Institute, Bijenicka cesta 54, 10000 Zagreb, Croatia.

Received: 29 December 2015 Accepted: 4 May 2016

Published online: 27 May 2016

\footnotetext{
References

1. Sims RJ, Reinberg D. Is there a code embedded in proteins that is based on post translational modifications? Nat Rev Mol Cell Biol. 2008;9:815.

2. Sarma K, Margueron R, Ivanov A, Pirrotta V, Reinberg D. Ezh2 requires PHF1 to efficiently catalyze $\mathrm{H3}$ lysine 27 trimethylation in vivo. Mol Cell Biol. 2008;28:2718

3. Prezioso C, Orlando V. Polycomb proteins in mammalian cell differentiation and plasticity. FEBS Lett. 2011;585:2067.

4. Grossniklaus U, Paro R. Transcriptional silencing by Polycomb-Group proteins. Cold Spring Harb Perspect Biol. 2014;6:a019331.

5. Lewis EB. A gene complex controlling segmentation in Drosophila. Nature. 1978;276:565.
} 
6. Whitcomb SJ, Basu A, Allis CD, Bernstein E. Polycomb group proteins: An evolutionary perspective. Trends Genet. 2007;23:494.

7. Shaver S, Casas-Mollano JA, Cerny RL, Cerutti H. Origin of the polycomb repressive complex 2 and gene silencing by an $\mathrm{E}(\mathrm{z})$ homolog in the unicellular alga Chlamydomonas. Epigenetics. 2010;5:301.

8. Dumesic PA, Homer CM, Moresco JJ, Pack LR, Shanle EK, Coyle SM, et al. Product binding enforces the genomic specificity of a yeast polycomb repressive complex. Cell. 2015;160:204.

9. Tschiersch B, Hofmann A, Krauss V, Dorn R, Korge G, Reuter G. The protein encoded by the Drosophila position-effect variegation suppressor gene Su(var)3-9 combines domains of antagonistic regulators of homeotic gene complexes. EMBO J. 1994;13:3822.

10. Strome S, Kelly WG, Ercan S, Lieb JD. Regulation of the X chromosomes in C. elegans. Cold Spring Harb Perspect Biol. 2014;6:a018366.

11. Baulcombe DC, Dean C. Epigenetic regulation in plant responses to the environment. Cold Spring Harb Perspect Biol. 2014;6:a019471.

12. Deb G, Singh AK, Gupta S. EZH2: not EZHY (easy) to deal. Mol Cancer Res. 2014;12:639.

13. Kuzmichev A, Jenuwein T, Tempst P, Reinberg D. Different EZH2-containing complexes target methylation of histone $\mathrm{H} 1$ or nucleosomal histone $\mathrm{H} 3$. Mol Cell. 2004:14:183.

14. Kuzmichev A, Margueron R, Vaquero A, Preissner TS, Scher M, Kirmizis A, et al. Composition and histone substrates of polycomb repressive group complexes change during cellular differentiation. Proc Natl Acad Sci U S A. 2005;102:1859.

15. Landeira D, Sauer S, Poot R, Dvorkina M, Mazzarella L, Jørgensen HF, et al. Jarid2 is a PRC2 component in embryonic stem cells required for multilineage differentiation and recruitment of PRC1 and RNA Polymerase II to developmental regulators. Nat Cell Biol. 2010;12:618.

16. Pasini $D$, Malatesta $M$, Jung $H R$, Walfridsson J, Willer $A$, Olsson $L$, et al. Characterization of an antagonistic switch between histone H3 lysine 27 methylation and acetylation in the transcriptional regulation of Polycomb group target genes. Nucleic Acids Res. 2010;38:4958.

17. Margueron R, Reinberg D. The Polycomb complex PRC2 and its mark in life. Nature. 2011:469:343.

18. Kim H, Kang K, Kim J. AEBP2 as a potential targeting protein for Polycomb Repression Complex PRC2. Nucleic Acids Res. 2009:37:2940.

19. Li G, Margueron R, Ku M, Chambon P, Bernstein BE, Reinberg D. Jarid2 and PRC2, partners in regulating gene expression. Genes Dev. 2010;24:368.

20. Song J-J, Garlick JD, Kingston RE. Structural basis of histone H4 recognition by p55. Genes Dev. 2008;22:1313.

21. Margueron R, Justin N, Ohno K, Sharpe ML, Son J, Drury WJ, et al. Role of the polycomb protein EED in the propagation of repressive histone marks. Nature. 2009:461:762

22. Brockdorff N, Turner B. Dosage compensation in mammals. Cold Spring Harb Perspect Biol. 2015;7:a019406.

23. Swiezewski S, Liu F, Magusin A, Dean C. Cold-induced silencing by long antisense transcripts of an Arabidopsis Polycomb target. Nature. 2009;462:799.

24. Chen WM, Huang MD, Sun DP, Kong R, Xu TP, Xia R, et al. Long intergenic non-coding RNA 00152 promotes tumor cell cycle progression by binding to EZH2 and repressing p15 and p21 in gastric cancer. Oncotarget. 2016. doi:10.18632/oncotarget.6949.

25. Chanvivattana Y, Bishopp A, Schubert D, Stock C, Moon YH, Sung ZR, et al. Interaction of Polycomb-group proteins controlling flowering in Arabidopsis. Development. 2004;131:5263.

26. Weaver DD, Graham CB, Thomas IT, Smith DW. A new overgrowth syndrome with accelerated skeletal maturation, unusual facies, and camptodactyly. J Pediatr. 1974;84:547.

27. Tatton-Brown K, Murray A, Hanks S, Douglas J, Armstrong R, Banka S, et al. Weaver syndrome and EZH2 mutations: Clarifying the clinical phenotype. Am J Med Genet A. 2013;161A:2972

28. Hobert $\mathrm{O}$, Jallal $\mathrm{B}$, Ullrich A. Interaction of Vav with ENX-1, a putative transcriptional regulator of homeobox gene expression. Mol Cell Biol. 1996;16:3066

29. Bracken AP, Pasini D, Capra M, Prosperini E, Colli E, Helin K. EZH2 is downstream of the PRB-E2F pathway, essential for proliferation and amplified in cancer. EMBO J. 2003:22:5323.

30. Morin RD, Johnson NA, Severson TM, Mungall AJ, An J, Goya R, et al. Somatic mutations altering EZH2 (Tyr641) in follicular and diffuse large Bcell lymphomas of germinal-center origin. Nat Genet. 2010;42:181.

31. Hodis E, Watson IR, Kryukov GV, Arold ST, Imielinski M, Theurillat JP, et al. A landscape of driver mutations in melanoma. Cell. 2012;150:251.
32. McCabe MT, Graves AP, Ganji G, Diaz E, Halsey WS, Jiang Y, et al. Mutation of A677 in histone methyltransferase EZH2 in human B-cell lymphoma promotes hypertrimethylation of histone $\mathrm{H} 3$ on lysine 27 (H3K27). Proc Natl Acad Sci U S A. 2012:109:2989.

33. Majer CR, Jin L, Scott MP, Knutson SK, Kuntz KW, Keilhack H, et al. A687V EZH2 is a gain-of-function mutation found in lymphoma patients. FEBS Lett. 2012;586:3448.

34. Sneeringer CJ, Scott MP, Kuntz KW, Knutson SK, Pollock RM, Richon VM, et al. Coordinated activities of wild-type plus mutant EZH2 drive tumorassociated hypertrimethylation of lysine 27 on histone H3 (H3K27) in human B-cell lymphomas. Proc Natl Acad Sci U S A. 2010;107:20980.

35. Fujikawa D, Nakagawa S, Hori M, Kurokawa N, Soejima A, Nakano K, et al: Polycomb-dependent epigenetic landscape in adult T-cell leukemia. Blood. 2016, doi:10.1182/blood-2015-08-662593.

36. Tsang DP, Wu WK, Kang W, Lee YY, Wu F, Yu Z, et al: Yin Yang 1-mediated epigenetic silencing of tumour-suppressive microRNAs activates nuclear factor-kB in hepatocellular carcinoma. J Pathol. 2016, doi:10.1002/path.4688.

37. Pan X, Papasani M, Hao Y, Calamito M, Wei F, Quinn lii WJ, et al. YY1 controls Igk repertoire and B cell development, and localizes with condensin on the Igk locus. EMBO J. 2013;32:1168.

38. Zhang Q, Padi SK, Tindall DJ, Guo B. Polycomb protein EZH2 suppresses apoptosis by silencing the proapoptotic miR-31. Cell Death Dis. 2014;5:e1486.

39. Popovic R, Martinez-Garcia E, Giannopoulou EG, Zhang Q, Zhang Q, Ezponda T, et al. Histone methyltransferase MMSET/NSD2 alters EZH2 binding and reprograms the myeloma epigenome through global and focal changes in H3K36 and H3K27 methylation. PLoS Genet. 2014;10:e1004566.

40. Agarwal P, Alzrigat M, Párraga AA, Enroth S, Singh U, Ungerstedt J, et al. Genome-wide profiling of histone $\mathrm{H} 3$ lysine 27 and lysine 4 trimethylation in multiple myeloma reveals the importance of Polycomb gene targeting and highlights EZH2 as a potential therapeutic target. Oncotarget. 2016. doi 10.18632/oncotarget.6843.

41. Hernando H, Gelato KA, Lesche R, Beckmann G, Koehr S, Otto S, et al. EZH2 inhibition blocks multiple myeloma cell growth through upregulation of epithelial tumor suppressor genes. Mol Cancer Ther. 2016;15:287.

42. Khan SN, Jankowska AM, Mahfouz R, Dunbar AJ, Sugimoto Y, Hosono N et al. Multiple mechanisms deregulate $\mathrm{EZ} \mathrm{H} 2$ and histone $\mathrm{H} 3$ lysine 27 epigenetic changes in myeloid malignancies. Leukemia. 2013:27:1301.

43. Mochizuki-Kashio M, Aoyama K, Sashida G, Oshima M, Tomioka T, Muto T, et al. Ezh2 loss in hematopoietic stem cells predisposes mice to develop heterogeneous malignancies in an Ezh1-dependent manner. Blood. 2015;126:1172.

44. Wassef M, Rodilla V, Teissandier A, Zeitouni B, Gruel N, Sadacca B, et al: Impaired PRC2 activity promotes transcriptional instability and favors breast tumorigenesis. Genes Dev. 2015 (in press, doi: 10.1101/gad.269522.115).

45. Coyle D, Friedmacher F, Puri P. The association between Hirschsprung's disease and multiple endocrine neoplasia type 2a: a systematic review. Pediatr Surg Int. 2014;30:751

46. Grzenda A, Lomberk G, Svingen P, Mathison A, Calvo E, lovanna J, et al. Functional characterization of $E Z \mathrm{H} 2 \beta$ reveals the increased complexity of $\mathrm{EZH} 2$ isoforms involved in the regulation of mammalian gene expression. Epigenetics Chromatin. 2013;6:3.

47. Wojtuszkiewicz A, Assaraf YG, Maas MJ, Kaspers GJ, Jansen G, Cloos J. PremRNA splicing in cancer: the relevance in oncogenesis, treatment and drug resistance. Expert Opin Drug Metab Toxicol. 2015;11:673.

48. Novak Kujundžić $R$, Grbeša I, Ivkić M, Krušlin B, Konjevoda P, Gall Trošelj K. Possible prognostic value of BORIS transcript variants ratio in laryngeal squamous cell carcinomas - a pilot study. Pathol Oncol Res. 2014;20:687.

49. Lee ST, Li Z, Wu Z, Aau M, Guan P, Karuturi RK, et al. Context-specific regulation of NF-KB target gene expression by EZH2 in breast cancers. Mol Cell. 2011:43:798.

50. Yan M, Zhang Y, He B, Xiang J, Wang ZF, Zheng FM, et al. IKKa restoration via EZH2 suppression induces nasopharyngeal carcinoma differentiation. Nat Commun. 2014:5:3661.

51. Xin Y, Lu Q, Li Q. IKK1 control of epidermal differentiation is modulated by notch signaling. Am J Pathol. 2011;178:1568.

52. Kim KH, Kim W, Howard TP, Vazquez F, Tsherniak A, Wu JN, et al. SWI/SNFmutant cancers depend on catalytic and non-catalytic activity of EZH2. Nat Med. 2015;21:1491

53. Wei Y, Chen YH, Li LY, Lang J, Yeh SP, Shi B, et al. CDK1-dependent phosphorylation of $\mathrm{EZH} 2$ suppresses methylation of $\mathrm{H} 3 \mathrm{~K} 27$ and promotes 
osteogenic differentiation of human mesenchymal stem cells. Nat Cell Biol. 2011;13:87.

54. Riquelme E, Behrens C, Lin HY, Simon G, Papadimitrakopoulou V, Izzo J, et al. Modulation of EZH2 expression by MEK-ERK or PI3K-AKT signaling in lung cancer is dictated by different KRAS oncogene mutations. Cancer Res. 2016;76:675.

55. Kim E, Kim M, Woo DH, Shin Y, Shin J, Chang N, et al. Phosphorylation of EZH2 activates STAT3 signaling via STAT3 methylation and promotes tumorigenicity of glioblastoma stem-like cells. Cancer Cell. 2013;23:839.

56. Serresi M, Gargiulo G, Proost N, Siteur B, Cesaroni M, Koppens M, et al. Polycomb Repressive Complex 2 is a barrier to KRAS-driven inflammation and Epithelial-Mesenchymal transition in non-small-cell lung cancer. Cancer Cell. 2016;29:17.

57. Oshima M, Hasegawa N, Mochizuki-Kashio M, Muto T, Miyagi S, Koide S, et al. Ezh2 regulates the Lin28/let-7 pathway to restrict activation of fetal gene signature in adult hematopoietic stem cells. Exp Hematol. 2016. doi: 10.1016/..exphem.2015.12.009.

58. Beachy SH, Onozawa M, Chung YJ, Slape C, Bilke S, Francis P, et al. Enforced expression of Lin28b leads to impaired T-cell development, release of inflammatory cytokines, and peripheral T-cell lymphoma. Blood. 2012;120:1048.

59. Zhao E, Maj T, Kryczek I, Li W, Wu K, Zhao L, et al. Cancer mediates effector $\mathrm{T}$ cell dysfunction by targeting microRNAs and $\mathrm{EZH} 2$ via glycolysis restriction. Nat Immunol. 2016;17:95.

60. Holm K, Grabau D, Lövgren K, Aradottir S, Gruvberger-Saal S, Howlin J, et al. Global H3K27 trimethylation and EZH2 abundance in breast tumor subtypes. Mol Oncol. 2012;6:494.

61. Palma G, Frasci G, Chirico A, Esposito E, Siani C, Saturnino C, et al. Triple negative breast cancer: looking for the missing link between biology and treatments. Oncotarget. 2015;6:26560.

62. Bae WK, Yoo KH, Lee JS, Kim Y, Chung IJ, Park MH, et al. The methyltransferase $\mathrm{EZH} 2$ is not required for mammary cancer development, although high $\mathrm{EZH} 2$ and low $\mathrm{H} 3 \mathrm{~K} 27 \mathrm{me} 3$ correlate with poor prognosis of ER-positive breast cancers. Mol Carcinog. 2015;54:1172.

63. Wei Y, Xia W, Zhang Z, Liu J, Wang H, Adsay NV, et al. Loss of trimethylation at lysine 27 of histone $\mathrm{H} 3$ is a predictor of poor outcome in breast, ovarian, and pancreatic cancers. Mol Carcinog. 2008:47:701e706.

64. Chen X, Song N, Matsumoto K, Nanashima A, Nagayasu T, Hayashi T, et al. High expression of trimethylated histone $\mathrm{H} 3$ at lysine 27 predicts better prognosis in non-small cell lung cancer. Int J Oncol. 2013;43:1467.

65. Yang YA, Yu J. EZH2, an epigenetic driver of prostate cancer. Protein Cell. 2013:4:331.

66. Shakhova O. Neural crest stem cells in melanoma development. Curr Opin Oncol. 2014;26:215.

67. Bachmann IM, Halvorsen OJ, Collett K, Stefansson IM, Straume O, Haukaas $\mathrm{SA}$, et al. EZH2 expression is associated with high proliferation rate and aggressive tumor subgroups in cutaneous melanoma and cancers of the endometrium, prostate, and breast. J Clin Oncol. 2006;24:268.

68. Zingg D, Debbache J, Schaefer SM, Tuncer E, Frommel SC, Cheng PL, et al. The epigenetic modifier EZH2 controls melanoma growth and metastasis through silencing of distinct tumour suppressors. Nat Commun. 2015;6:6051.

69. Morera L, Lübbert $M$, Jung $M$. Targeting histone methyltransferases and demethylases in clinical trials for cancer therapy. Clin Epig, Review Series "Epigenetic drugs- from chemistry via biology to medicine and back" (in press).

\section{Submit your next manuscript to BioMed Central and we will help you at every step:}

- We accept pre-submission inquiries

- Our selector tool helps you to find the most relevant journal

- We provide round the clock customer support

- Convenient online submission

- Thorough peer review

- Inclusion in PubMed and all major indexing services

- Maximum visibility for your research

Submit your manuscript at www.biomedcentral.com/submit

Biomed Central 